\title{
REMINISCENNCIAS VIRGILIANAS NA OBRA DO HUMANISTA INÁCIO DE MORAIS
}

\author{
Aires Pereira do Couto \\ Universidade Católica Portuguesa - CECH da Universidade de Coimbra
}

\section{Resumo}

Seguindo um dos preceitos da criação poética no Renascimento, era habitual a imitação ou transcrição de expressões, frases, versos, ou o recurso a exempla clássicos greco-latinos.

No conjunto das fontes da obra do poeta e humanista português Inácio de Morais, destaca-se o poeta latino Virgílio, cujas reminiscências se encontram profusamente disseminadas ao longo da obra de Inácio de Morais. As marcas e ecos das leituras da obra virgiliana ressoavam no espírito do humanista português, que delas transcreveu ou adaptou versos inteiros, hemistíquios, ou simples expressões, ou nelas se inspirou para ilustrar acontecimentos, através de oportunos paralelismos ou comparações entre figuras ou factos.

Este estudo revela os ecos do mantuano na obra de Inácio de Morais e mostra como este soube inspirar-se, com notável mestria e sensibilidade, nos tons virgilianos para dar ainda maior brilho e majestade às suas inspiradas obras.

Palavras-chave: Renascimento, Humanismo, exempla, Virgílio, Inácio de Morais.

\section{VIRGILIAN REMINISCENCES IN THE WORK OF HUMANIST IGNATIUS DE MORAIS}

Abstract

Following one of the precepts of poetic creation in Renaissance, it was common to imitate or transcribe expressions, phrases, verses, or use Greco-Latin classical exempla.

From all sources of the work of the Portuguese poet and humanist Ignatius de Morais, the Latin poet Virgil stands out; his reminiscences are widely disseminated throughout the work of Ignatius de Morais. The traces and echoes from the readings of the Virgilian work resounded in the spirit of the Portuguese humanist, who transcribed 
or adapted whole verses, hemistiches, or simple expressions, or drew on them to illustrate events through appropriate parallels or comparisons between figures or facts.

This study reveals the echoes of the Mantuan in the work of Ignatius de Morais and shows how he was able to draw, with remarkable mastery and sensitivity, on the Virgilian tones to give an even greater brilliance and majesty to his inspired works.

Keywords: Renaissance, Humanism, exempla, Virgil, Ignatius de Morais.

Era prática corrente, nas obras dos autores renascentistas, a imitação, adaptação, ou simplesmente transcrição de expressões, frases, versos, ou passos mais ou menos longos de modelos clássicos grecolatinos, dos textos bíblicos, e até dos próprios humanistas. Seguindo a recomendação horaciana que aconselhava a leitura e imitação dos modelos gregos, que a perfeição elevara a paradigmas (Arte poética 268269), e a de Quintiliano que, porque considerava que uma parte importante da arte tinha a sua base na imitação, propunha que dos autores dignos de serem lidos se tomasse a riqueza das suas palavras, a variedade de figuras e o modo de compor as frases (Inst. Or. 10.2.1), os quinhentistas insistiam na necessidade de imitar os clássicos, um dos preceitos fundamentais da criação poética. António Ferreira, na Carta XII a Diogo Bernardes, faz um elogio da imitação e da erudição:

Na boa imitação, e uso, que o fero ingenho abranda, ao inculto dá arte, no conselho do amigo douto espero.

$$
[\ldots]
$$

Do bom escrever, saber primeiro é fonte.

Enriquece a memória de doutrina, do que um cante, outro ensine, outro te conte (Ferreira, 2000: 305306).

Mas essa imitação não podia ser um decalque, ela devia apenas aproveitar alguns aspectos de conteúdo e de forma de um ou vários modelos, no intuito de criar obras tão perfeitas e originais quanto possível $^{1}$. Por isso, como afirma Soares (2018: 147), «A imitação dos

\footnotetext{
${ }^{1}$ Sobre a questão da imitação dos modelos greco-latinos entre os renascentistas, Buck (1980), Martín Acera (1987), García Galiano (1992), Soares (1993 e 2018), McLaughlin
} 
modelos clássicos, a multiplex imitatio, apoiada na prática da memória e na ars combinatoria, tendo sempre em conta o decorum, é posta em prática nas exercitationes da pedagogia quinhentista, muito para além da simples repetitio».

Também o conhecimento das leituras dos autores renascentistas, feito através do estudo das fontes, se revela da maior importância para se inferir das suas preocupações e interesses literários. Embora os autores do Renascimento tenham, amiúde, deixado pistas que remetem para o modelo ou modelos subjacentes à sua produção literária, a identificação dessas fontes é, no entanto, por vezes difícil, pois os humanistas nem sempre as identificam claramente e, muitas vezes, elas não passam de reminiscências mais ou menos vagas que, frequentemente, não resultavam da leitura direta das obras dos diferentes autores, mas eram obtidas através da leitura de coletâneas, onde se organizavam tematicamente excertos de obras de diferentes autores, ou de antologias de lugarescomuns, de sentenças várias e de informações históricas ${ }^{2}$.

A obra de Inácio de Morais $^{3}$-um poeta que Jerónimo Cardoso considera «sem par, a quem louva o coro das nove sábias deusas» (Elegiarum liber II, 1563, fol.Bvj), e de quem Diogo Mendes de Vasconcelos diz, no seu poema De suo ex Ebora discessu v.39, que «deve ser comparado com os poetas antigos»- não foge a esta regra, não só porque as suas citações nem sempre têm a indicação do autor e/ou da obra, mas sobretudo porque as suas fontes são habitualmente adaptadas ou mesmo apresentadas de forma muito geral, não passando, muitas vezes, de meras

(2001), Galán Sánchez (2007), Castro (2008), Saltarelli (2009), Melo (2011), Martín Jiménez (2015), Pérez (2015), Santos (2016), Soares e Teixeira (2017), Martí (2017).

2 O Viridarium, de Octaviano Mirandula, os Epitheta, de João Ravísio Textor, e a Polyanthea, de Domenico Nano Mirabello, publicados, respetivamente, em 1507, 1524 e 1526, são, entre outros, exemplos de algumas das coletâneas que os autores quinhentistas podiam consultar. Estas coletâneas funcionavam como verdadeiras enciclopédias gerais ou especializadas, onde os humanistas encontravam os passos mais importantes dos autores clássicos greco-latinos, dos medievais, dos humanistas, da Bíblia e da patrística, em áreas diversas como a história, a mitologia, a filosofia, a religião, a poesia, etc. Cf. Pinho (1987: 227).

3 Professor, poeta e orador novilatino português, Inácio de Morais nasceu em Bragança, no início do século XVI. Sobre o percurso biográfico e literário deste importante Humanista português, Couto (2004). 
alusões, o que dificulta efetivamente a identificação de muitos dos textos e autores que lhe serviram de fonte.

No conjunto dessas fontes, que abarcam autores gregos, latinos, do Renascimento, e textos bíblicos, sobressaem os ecos da presença de mais de vinte autores latinos. Entre estes destaca-se, pela influência que exerceu nos autores do Renascimento, em geral, e no poeta brigantino, em particular, Virgílio, que Inácio de Morais, numa composição poética inserida na Oratio panegyrica ad inuictissimum Lusitaniae regem diuum Ioannem tertium, considera 'o grande poeta da Ausónia' (ingens Ausoniae uates).

Virgílio era, habitualmente, tido como o mais sábio dos escritores antigos. Aliás, as referências a ele feitas por Cataldo, na carta que dirige a D. Fernando de Meneses, $2^{\circ}$ Marquês de Vila Real, são bem elucidativas do estatuto que detinha entre os humanistas e que fez dele, efetivamente, um dos poetas latinos mais lidos pelos humanistas e que mais os inspirou. Na referida carta de Cataldo, escrita nos últimos meses de 1499 ou Janeiro / Fevereiro de $1500^{4}$, e publicada no primeiro dos dois volumes das Epistolae et orationes quaedam Cataldi Siculi (Lisboa, Valentim Fernandes, 21 de Fevereiro de 1500) $)^{5}$, o Humanista italiano faz, entre nós, a primeira defesa das Humanidades e do latim literário, contra «certos teólogos de meia-tigela», que, "para se darem ares de mais doutos e mais santos entre os néscios, com ares seráficos, não só dizem mal de um grande e eminente poeta, célebre entre os homens, como Virgílio, mas rasgam sem piedade a própria língua latina, dizendo que deve ser banida da prática dos homens, como se fosse indigna de aparecer perante eles». Os referidos 'teólogos de meia-tigela' (theologiculos) procuravam, segundo Cataldo, afastar da leitura dos poetas os filhos dos nobres «porque incitam à luxúria o pensamento dos homens, com o seu vocabulário provocante e erótico (como se apenas fosse libidinoso quem lê os poetas)» e sob pretexto de que a cultura pagã era inimiga da fé e dos

\footnotetext{
${ }^{4}$ Cf. Ramalho (1985: VII). Ramalho (1985: 41-53) traduziu e publicou esta carta.

${ }^{5}$ Em 1988, A. C. Ramalho publicou uma edição fac-similada desta obra, com uma introdução da sua autoria: Cataldo Parísio Sículo, Epistolae et Orationes, Acta Vniversitatis Conimbrigensis, Coimbra.

${ }^{6}$ A tradução dos excertos da carta de Cataldo a D. Fernando de Meneses aqui transcritos é de Ramalho.
} 
bons costumes. Cataldo procurou rebatê-los, contrapondo a autoridade dos padres da Igreja que recomendavam a leitura de vários autores latinos. Entre esses autores sobressai um: Virgílio, a propósito do qual Cataldo sugere que se ouçam as palavras com que Santo Agostinho se lhe refere no primeiro livro da Cidade de Deus: "Virgílio que os pequenos lêem, naturalmente como um grande poeta e de todos o mais ilustre e excelente, e que, assimilado em tenros anos, não poderá ser facilmente esquecido». Palavras que merecem de Cataldo o seguinte comentário, em jeito de apelo: «Considera as palavras de Agostinho, peço-te, ó varão romano, quem quer que tu sejas, palavras proferidas em louvor de Virgílio, contra os literatelhos do nosso tempo, que feridos quer de inveja, quer sob o peso da ignorância, dilaceram tão sublime vate quase diariamente, com a maior insolência e a maior impiedade».

Perante este prestígio de Virgílio entre os humanistas, não é de estranhar que as reminiscências virgilianas estejam profusamente disseminadas na obra do Humanista Inácio de Morais, particularmente nas composições em verso, e rivalizem, em quantidade, com as de Horácio, Cícero, e, especialmente, com as de Ovídio ${ }^{7}$, de tal modo que, já no século XVIII, Barbosa Machado observava que Inácio de Morais se distinguira «no estudo das letras humanas e na metrificação dos Versos Latinos em que imitou a Magestade de Virgílio e a suavidade de Ovídio» (Machado, 1965-1967: 544-545).

Fixemo-nos agora nas reminiscências virgilianas dispersas pelas composições poéticas do Humanista, começando pelas da Eneida.

No poema In interitum principis Ioannis -uma composição poética publicada em 1554, onde, ao longo de 75 dísticos elegíacos, é lamentada a morte do príncipe João, ocorrida em 2 de Janeiro de 1554, o único filho que restava a D. João III e a D. Catarina, acontecimento fatídico que deixou todo o país em profundo luto e angustiado pela incerteza do futuro- Inácio de Morais alude, nos vv. 53-54 desta composição, à dor sentida por Augusto no momento da morte de Marcelo, para salientar que a do príncipe D. João foi mais dolorosa para D. João III do que a de Marcelo para Augusto:

7 André de Resende considera Inácio de Morais um poeta uenae facillimae et Ouidianae. Cf. Pereira (2000a: 345). Sobre as reminiscências ovidianas na obra de Inácio de Morais, Couto (2004: 233-239) e Pereira (2000b: 753-769). 
Nec dolor Augusti Marcelli in funere tantus, quem fleuit lacrimis Martia Roma piis .

Saliente-se que, tal como o príncipe D. João estava destinado a suceder a D. João III, também Augusto tencionava fazer de Marco Cláudio Marcelo -um jovem dotado de invulgares qualidades e que era seu sobrinho e genro- o seu sucessor.

Alguns anos mais tarde, em 1578, na 'Elegia à morte de D. Catarina', intitulada In interitum D. Catharinae Lusitaniae reginae, em que o poeta relembra, ao longo de 57 dísticos elegíacos, as qualidades ímpares da rainha, Inácio de Morais volta a referir-se à morte de Marcelo, agora para comparar, nos versos 99-100, as lamentações que marcaram o funeral da rainha D. Catarina, junto ao rio Tejo, com as que aconteceram em Roma, junto ao Tibre, quando o jovem Marcelo morreu:

Consimiles planctus Tiberini ad fluminis undas, cum Marcellus obit Martia Roma dedit.

É provável que estas duas referências comparativas tenham sido inspiradas no relato que, no livro VI da Eneida, Anquises fez a Eneias, evocando a morte prematura do jovem M. Cláudio Marcelo:

Atque hic Aeneas (una namque ire uidebat egregium forma iuuenem et fulgentibus armis, sed frons laeta parum et deiecto lumina uoltu): "Quis, pater, ille, uirum qui sic comitatur euntem? filius, anne aliquis magna de stirpe nepotum? Qui strepitus circa comitum! quantum instar in ipso! Sed nox atra caput tristi circumuolat umbra.» Tum pater Anchises lacrimis ingressus obortis: «O nate, ingentem luctum ne quaere tuorum: ostendent terris hunc tantum fata neque ultra

\footnotetext{
${ }^{8}$ A tradução de todos os versos ou excertos de textos de Inácio de Morais transcritos neste estudo pode ser consultada em Couto (2004).
} 
esse sinent. Nimium uobis Romana propago uisa potens, superi, propria haec si dona fuissent. Quantos ille uirum magnam Mauortis ad urbem campus aget gemitus! uel quae, Tiberine, uidebis funera, cum tumulum praeterlabere recentem! Nec puer Iliaca quisquam de gente Latinos in tantum spe tollet auos, nec Romula quondam ullo se tantum tellus iactabit alumno. Heu pietas, heu prisca fides inuictaque bello dextera! Non illi se quisquam impune tulisset obuius armato, seu cum pedes iret in hostem seu spumantis equi foderet calcaribus armos. Heu, miserande puer, si qua fata aspera rumpas! Tu Marcellus eris. Manibus date lilia plenis, purpureos spargam flores animamque nepotis his saltem accumulem donis, et fungar inani munere [...] $(6.860-886)^{9}$.

Na já referida elegia In interitum principis Ioannis, Inácio de Morais, num incitamento hiperbólico, apela às lágrimas e à mortificação para que a expressão da dor iguale a enormidade da desgraça que a morte do príncipe D. João representava $^{10}$ :

Flere licet; planctu contundite pectora ciues; regia maestificis luctibus aula fremat.

Femineique greges, uestros lacerate capillos, infesto teneras ungue notate genas (81-84).

\footnotetext{
${ }^{9}$ As edições que serviram de base à transcrição dos textos virgilianos foram as da «Les Belles Lettres» (Virgílio, 1977-1980, 1982 e 1983).

${ }^{10}$ Sobre o modo como Inácio de Morais retrata a morte do príncipe D. João e a ansiedade que se lhe seguiu, Couto (2003: 681-701).
} 
Ao pedir aos cidadãos que oprimam os seus peitos com o pranto; que o palácio real ressoe com os tristes lutos e que as mulheres arranquem os seus cabelos e lacerem as tenras faces com as unhas agressivas, Inácio de Morais alude a algumas formas de violência que, entre os Antigos, o pranto público tomava, e que Virgílio refere em vários momentos da Eneida, como quando, nos versos 479-482 do livro I, as mulheres troianas, tristes, batem com as mãos no peito ao dirigirem-se ao templo da hostil Palas; ou quando, nos versos 589-590 do livro IV, a rainha Dido bate várias vezes com o punho no peito e dilacera os cabelos ao aperceber-se da partida de Eneias; e ainda quando, logo a seguir, nos versos 672-673, a sua irmã Ana dilacera o rosto com as unhas e fere o peito com os punhos perante o suicídio cometido por Dido. Também o velho Acetes, no livro XI, maltrata o peito com os punhos e o rosto com as unhas ao longo do cortejo fúnebre do seu querido pupilo Palante (vv.85-86). Atitude semelhante tomou a irmã de Turno, a ninfa Juturna, no final da Eneida, quando, ao aperceber-se do silvo das asas da Fúria, reconhece o fúnebre aviso e abandona o campo de batalha (12.869-871).

O verso 119 do In interitum principis Ioannis é uma adaptação, muito aproximada, do verso 582 do livro IV da Eneida, a que Inácio de Morais terá recorrido para comparar a quantidade de navios que encheram o estuário do Tejo, aquando da chegada de Espanha da princesa D. Joana, com o número de barcos da frota de Eneias, quando ele decidiu partir, abandonando a rainha Dido:

A. 4.582: Litora deseruere, latet sub classibus aequor.

Morais: Litoreum densis latuit sub classibus aequor.

Também os versos 135-138 da mesma composição:

Infans nascatur Ioannis postuma proles, pondera qui regni, sceptraque auita gerat.

In quem Lysiadum domus inclinata recumbat, qui tibi, qui nobis mite leuamen erat.

parecem revelar influência da Eneida de Virgílio:

Turne, per has ego te lacrimas, per si quis Amatae 
tangit honos animum (spes tu nunc una, senectae tu requies miserae, decus imperiumque Latini te penes, in te omnis domus inclinata recumbit), unum oro: desiste manum committere Teucris (12.56-60).

De facto, assim como o Mantuano pôs, a propósito da incerteza no futuro da casa real, a rainha Amata a suplicar a Turno que deixasse de combater os Troianos, não só porque ele era a única esperança e segurança da sua pobre velhice, mas também porque a honra e o poder de Latino estavam nas suas mãos, e toda a casa que então vacilava se apoiava nele, assim também Inácio de Morais suplica à princesa D. Joana que não afrouxe os freios à sua dor e possa dar à luz a prole póstuma do Príncipe D. João, o futuro rei D. Sebastião, para que ele chame a si os cuidados do reino e o ceptro dos antepassados, e que nele se apoie a vacilante casa dos Lusíadas.

Os mesmos versos virgilianos terão também servido de fonte aos versos 91-92 da 'Elegia à morte do rei D. João III', In interitum serenissimi regis Lusitanorum Ioannis tertii, nos quais Inácio de Morais apela, após a morte de D. João III, para a proteção do Cardeal D. Henrique, em quem a vacilante Casa Real se apoia para governar o povo e reino lusitano:

In te nunc fratris domus inclinata recumbit,

tu nos et fratris regna tuere tui.

Em ambos os casos, o poeta novilatino repete a quase totalidade do verso 59 do livro XII da Eneida.

Para exprimir a angústia e o desespero que D. Joana sentiu ao saber da morte do seu marido, o príncipe D. João, Inácio de Morais deixa transparecer, nos versos 43-44 do poema Deplorat Ioanna serenissima maritum -um poema que, ao longo de 83 dísticos elegíacos, coloca, na boca da princesa, aquelas que terão sido as suas reações quando tomou conhecimento do nefando acontecimento-, ecos dos versos 29-30 e 259260 do livro III da Eneida: os primeiros referentes ao calafrio que sacudiu os membros de Eneias e que lhe gelou o sangue quando, na Trácia, da primeira planta que arrancou do solo começaram a escorrer gotas de sangue; os segundos relativos ao pavor que gelou o sangue dos 
companheiros de Eneias depois de terem ouvido a Harpia Celeno revelar a profecia de Apolo, segundo a qual fundariam a sua cidade apenas depois de terem sido obrigados, pela fome, a comer as suas próprias mesas:

A. 3.29-30:

[...] Mihi frigidus horror

membra quatit gelidusque coit formidine sanguis.

A. 3.259-260: At sociis subita gelidus formidine sanguis deriguit; cecidere animi, nec iam amplius armis.

Morais: $\quad H e i$ mihi, diriguit gelidus mihi corpore sanguis, et stupor inclusit gutture uocis iter (43-44).

Nos versos 107-110 do mesmo poema Deplorat Ioanna serenissima maritum, a princesa D. Joana afirma que, apesar de todos lhe esconderem a trágica morte do seu marido por estar grávida e para não pôr em perigo o nascimento daquele que era a única esperança de salvação do reino -o futuro rei D. Sebastião-e que viria a nascer 18 dias depois da morte do príncipe D. João, a sua mente pressentia a desgraça:

Hoc, hoc illud erat tacite quod saepe putabat mens praesaga mali, sollicitusque metus.

Tristia me cuncti celabant fata mariti, et dicebatur sospes abesse domo.

$\mathrm{O}$ primeiro hemistíquio do verso 108 surge no livro $\mathrm{X}$ da Eneida, num contexto de dor semelhante ao que envolvia a princesa D. Joana, num momento em que a mente do chefe etrusco Mezêncio, pressentindo a desgraça, se apercebeu de que o pranto que ouvia ao longe se devia à morte do seu filho Lauso:

Agnouit longe gemitum praesaga mali mens (843).

Também os versos 126-127 do referido poema Deplorat Ioanna, em que D. Joana se lamenta de não ter podido despedir-se do marido, apresentam algumas semelhanças com dois versos da Eneida: um referente à rainha Dido, destroçada pela partida de Eneias (4.650), e outro ao chefe troiano Aletes, aquando da partida dos jovens guerreiros troianos (9.251): 
Morais: Non ergo licuit morientis cernere uultus, pallida nec lacrimis ora rigare meis.

Oscula nulla dedi nec uerba nouissima dixi, nec saltem extremum perpetuumque uale (125-128).

A. 4.650: Incubuitque toro dixitque nouissima uerba.

A. 9.251: Amborum et uoltum lacrimis atque ora rigabat.

A semelhança entre algumas das expressões presentes nestes dois versos de Virgílio e as usadas nos citados versos de Inácio de Morais sugere a fonte virgiliana dos citados versos do Humanista.

Saliente-se que o tema da morte do príncipe João inspirou numerosos poetas, que tinham nele um protetor, e que lhe dedicaram versos de profunda dor, quer em latim, quer em vernáculo. Das composições escritas em latim, para além das já referidas de Inácio de Morais, destacam-se as de Diogo de Teive: Tragoedia Ioannes Princeps e a Oratio funebris in laudem Ioannis, illustrissimi Lusitaniae Principis, publicadas em 1558, juntamente com outras composições, num volume intitulado Iacobi Teuii Bracarensis opuscula aliquot in laudem Ioannis tertii Lusitaniae regis, et principis eius filii, \& fratris Lodouici, atque item Sebastiani primi regis eiusdem nepotis. Quorum sequens pagella catalogum continet, Salmanticae, excudebant haeredes Ioannis a Iunta Floren. 1558; o In interitum D. Ioannis Lusitaniae Principis epicedium de António de Cabedo, publicado no final da edição de 1597 do De Antiquitatibus Lusitaniae de André de Resende; e também o De senectute de Lopo Serrão, liv. XII, vv. 683-816 (Pinho, 1987). Foram mais ainda os poetas que, em português, lamentaram a sua morte. É o caso de António Ferreira, num epitáfio, nas éclogas Jânio e Dáfnis, numa elegia dedicada a Francisco de Sá de Meneses, e numa carta dirigida a D. João III; Sá de Miranda, em elegia à morte de D. João; Pêro de Andrade Caminha, num epitáfio, num soneto e na elegia I; Diogo Bernardes, numa elegia e na écloga Adónis; Camões, na sua écloga I; e ainda outros como Jorge de Montemor, Jorge Ferreira de Vasconcelos, e D. Simão da Silveira ${ }^{11}$.

\footnotetext{
${ }^{11}$ Sobre o tema da morte do Príncipe D. João na poesia quinhentista, Teive (1999: 37-
} $57)$. 
Nos vv. 43-44 da elegia intitulada In interitum serenissimi regis Lusitanorum Ioannis tertii:

Tu nos, heu, mediis tanquam Palinurus in undis

deseris incertos, consiliique inopes.

É notório o paralelismo com a Eneida, ao ser comparada a morte de D. João III com a de Palinuro, o piloto de Eneias que, durante a noite, adormeceu e caiu ao mar, morrendo afogado e deixando o barco à deriva (cf. $A$. 5.835-71). Com esta comparação, Inácio de Morais faz uso da metáfora da nau do estado para ilustrar o facto de o reino ter ficado à deriva, como o barco de Eneias sem o piloto Palinuro.

De influência virgiliana parece ser também a evocação conjunta que Inácio de Morais faz, no poema In quosdam Dialecticos et Grammaticos, vv. 46-55, dos nomes de várias famílias romanas ilustres: os Cipiões, os Catões e os Décios, ou ainda de figuras individuais como Bruto $^{12}$ e Torquato ${ }^{13}$. A referida evocação destes exempla clássicos, feita num poema em que, ao longo de 167 hexâmetros dactílicos, Inácio de Morais elogia o Direito e intervém a favor dos juristas, na polémica entre humanistas e juristas ${ }^{14}$, parece deixar transparecer influência do segundo livro das Geórgicas e do livro VI da Eneida, onde todos eles aparecem referidos. Sublinhe-se ainda que, tal como Virgílio, também Inácio de Morais fez uso de antonomásias:

Morais: $\quad$ Inuiolata olim Romani iura Quirites

dum sancte obseruant, patrias legesque tuentur,

terrarum uicere orbem, famamque perennem

${ }^{12}$ O poeta evoca Lúcio Júnio Bruto, um dos principais causadores da expulsão do último rei de Roma, Tarquínio o Soberbo. Tornou-se o primeiro cônsul de Roma. Em 509 a.C. teve de condenar à morte os seus dois filhos, que tinham entrado numa coligação para restaurar a monarquia.

${ }^{13}$ Alusão ao cônsul T. Mânlio Torquato, que mandou matar o seu próprio filho, que havia vencido o inimigo, por este ter combatido sem a sua licença. A sua dureza disciplinar fez com que, ao regressar vitorioso a Roma, a juventude romana, como protesto contra o cruel ato por ele praticado, não estivesse presente na sua receção, só os velhos o receberam com aplausos. O cognome Torquato (portador de um colar) advém do facto de ele ter ficado com o colar de um gigante gaulês que venceu em combate.

${ }^{14}$ Sobre a posição de Inácio de Morais na polémica entre juristas e humanistas que, entre 1530 e 1540, dominou a vida pública portuguesa, Couto (2002). 
inuictis meruere armis. Hinc omne per aeuum

Scipiadae, et magna celebrantur laude Catones, et qui pro patriae se deuouere salute magnanimi Decii. Nec te quoque Brute silebo, quique hostem superans, de Torque est nomen adeptus; uos duo nam leto uestros damnastis acerbo natos, pro lege et pro libertate tuenda.

G. 2.169-170: [...] Decios, Marios, magnosque Camillos, Scipiadas duros bello [...]

A. 6.817-846: Vis et Tarquinios reges animamque superbam ultoris Bruti, fascisque uidere receptos? Consulis imperium hic primus saeuasque securis Accipiet, natosque pater noua bella mouentis ad poenam pulchra pro libertate uocabit, infelix! utcumque ferent ea facta minores: uincet amor patriae laudumque immensa cupido. Quin Decios Drusosque procul saeuomque securi aspice Torquatum et referentem signa Camillum (817-825). Quis te, magne Cato, tacitum aut te, Cosse, relinquat? Quis Gracchi genus aut geminos, duo fulmina belli, Scipiadas, cladem Libyae, paruoque potentem Fabricium uel te sulco, Serrane, serentem? Quo fessum rapitis, Fabii? Tu Maximus ille es, unus qui nobis cunctando restituis rem (841-846).

As reminiscências virgilianas têm também eco na comparação que, na já referida 'Elegia à morte de D. Catarina' (In interitum $D$. Catharinae Lusitaniae reginae), Inácio de Morais faz entre a rainha D. Catarina, Dido e Lavínia:

Coniuge tu fato functo moderata fuisti Lysiadum populos aequaque iura dabas. 
Sic iuste Tyrios rexit Sidonia Dido, quorum erat obsequiis culta et amata piis.

Sic quoque post fatum Aeneae Lauinia coniux ipsa uiri partes imperiumque subit (67-72).

O modo como D. Catarina governou o reino dos Lusíadas, após a morte de D. João III, é comparado com o governo da rainha Dido em Cartago, onde era amada e respeitada pela dedicada obediência dos seus súbditos, e com o de Lavínia que, após a morte de Eneias, assumiu o papel de regente, enquanto Ascânio não atingiu a maioridade (Tito Lívio 1.3.1-5). A comparação com Dido remete-nos imediatamente para a Eneida, onde Virgílio $(1.446 ; 1.613 ; 9.266 ; 11.74)$, aludindo à origem fenícia da rainha de Cartago, se refere a ela como Sidonia Dido, expressão que Inácio de Morais usa, colocando-a, também ele, em final de verso. O mesmo acontece em relação à comparação com Lavínia, já que o poeta novilatino faz uso da expressão Lauinia coniux em final de verso, à semelhança do que Virgílio fez por quatro vezes na Eneida $(6.764 ; 7.314 ; 12.17 ; 12.937)$. O uso das citadas expressões nas referidas comparações parecem não deixar dúvidas sobre a inspiração textual virgiliana dos versos 67-72 da elegia In interitum D. Catharinae Lusitaniae Reginae.

Também no poema Ad illustrissimum uirum Dom. Ludouicum de Ataide quondam Imperatorem Indicum, uma breve composição poética publicada pela primeira vez em 1575, nos Diuersorum auctorum carmina in laudem illustrissimi domini Ludouici Athaidii, serenissimi regis Portugalliae a consiliis, pro foelici uictoria apud Indos reportata, em que Inácio de Morais elogia, ao longo de 12 dísticos elegíacos, as qualidades guerreiras de D. Luís de Ataíde, parecem ecoar, nos versos 11-14, reminiscências de um passo do livro VI da Eneida-passo em que Anquises apresenta César Augusto como aquele que restaurará no Lácio a Idade do Ouro e alargará o Império para além dos Garamantes e dos Indianos:

A. 6.791-795: Hic uir, hic est, tibi quem promitti saepius audis,

Augustus Caesar, diui genus, aurea condet

saecula qui rursus Latio regnata per arua

Saturno quondam, super et Garamantas et Indos 
proferet imperium; [...]

Morais: $\quad T u$ bonus es miles, tuque optimus induperator, tu decus et gentis gloria rara tuae.

Caesare tu maior, superas Garamantas et Indos, famamque extendis iusta per arma tuam.

Para além das várias reminiscências da Eneida, presentes nas composições poéticas de Inácio de Morais, encontram-se também disseminadas na sua obra poética algumas referências que nos podem remeter para as Bucólicas enquanto fonte.

Uma surge no poema Ad nascentem prolem serenissimae Ioannae, dedicado a D. Sebastião, onde a dupla repetição, em anáfora e em epífora, da expressão nascere, parue puer, em cada um dos versos que compõem os 18 dísticos elegíacos do poema, retoma o paruus puer da Bucólica IV. Inácio de Morais parece recriar as expressões virgilianas nascenti puero (v. 8) e parue puer (vv. 60-62) e transforma-as na expressão nascere, parue puer, repetida trinta e oito vezes, para exprimir a ansiedade nacional pelo nascimento daquele que viria a ser o rei $\mathrm{D}$. Sebastião, que só nasceria 18 dias depois da morte do seu pai, o príncipe D. João, e que, já antes de nascer, encarnava a esperança num futuro promissor e era considerado a salvação do reino (nostra salus v. 4).

O virgiliano puer é retomado no poema Deplorat Ioanna serenissima maritum, quando Inácio de Morais repete, anaforicamente, nos versos 87-89, a expressão exi, care puer, pondo, agora na boca da princesa D. Joana, a expressão de ansiedade que então se vivia com a expectativa do nascimento de D. Sebastião e que já exprimira, como vimos, no poema Ad nascentem prolem serenissimae Ioannae.

Outra referência que indicia a influência das bucólicas virgilianas é a que encontramos no $M$. T. Ciceronis proaemium Rhetoricae ad Herennium ex prosa in carmen uersum, uma adaptação em verso do proémio da Retórica a Herénio, onde, no verso 5 do capítulo intitulado De exordio, Inácio de Morais transcreve, ipsis uerbis, o verso 60 da Bucólica III, que é uma forma de invocação habitual no início de um discurso ou de um poema (cf. Teócrito, 17.1; Arato, Phaen. 1.4) para, 
deste modo, dar um exemplo de como se pode começar um exórdio considerado vulgar:

Ab Ioue principium, Musae; Iouis omnia plena (3.60).

Por fim, no poema Academia conqueritur cur non reuertatur Arius Pinellus -uma elegia na qual a Universidade de Coimbra, numa prosopopeia da própria Academia, lamenta a ausência do jurista Aires Pinhel, que trocara Coimbra por Salamanca em 1559, e reclama o seu regresso à Alma Mater conimbricense- ecoa uma outra reminiscência das bucólicas virgilianas, que consiste no uso do nome Amarílis:

Morais: Hunc Amaryllis habet, quo me priuauerant ante,

hunc iterum pellex eripit ista mihi (7-8).

Ergo tolle moras! Contemne Amaryllidis ignes

et nostros retine. Sit tibi cura mei (31-32).

A explicação para a presença deste nome no poema de Inácio de Morais encontramo-la na Bucólica I (vv. 5, 30 e 36), onde Amarílis é o nome da nova paixão do pastor Títiro, que substituiu a anterior -Galateia. E é precisamente a uma nova paixão, mais especificamente à rival da Alma Mater Conimbricense -a Universidade de Salamanca, a concubina que roubou à Academia de Coimbra Aires Pinhel o seu amado mestre- que Inácio de Morais dá o nome de Amarílis.

As reminiscências virgilianas na obra de Inácio de Morais não se encontram apenas nas suas composições poéticas, elas surgem também em alguns textos em prosa, como acontece em duas cartas que o Humanista envia ao seu amigo Jerónimo Cardoso (publicadas in Jerónimo Cardoso, Epistolarum Familiarium Libellus, Olysipone, apud Ioannem Barrerium Typographum Regium, 1556, fls. $50 \mathrm{v}^{\mathrm{o}}-51 \mathrm{v}^{\mathrm{o}}$ e 53$\left.54 v^{\circ}\right)$. No início da carta que ocupa as fls. $50 v^{\circ}-51 v^{\circ}$, uma epístola com uma importância especial por nos informar que Jerónimo Cardoso pediu a Inácio de Morais que lhe fizesse a revisão do discurso que proferiu na Universidade de Lisboa em 1 de outubro de 1536, Inácio de Morais revela que gostaria de dispor de muito mais tempo livre para poder conversar com Jerónimo Cardoso sobre assuntos literários e ficar suspenso da sua boca, da qual sai um discurso mais doce do que o mel: 
Vellem Cardose, uir praeclare, longe maius mihi otium suppeteret ut tecum de re literaria colloquium miscere liberius possem, et mihi liceret assidue $a b$ isto ore pendere ex quo melle dulcior distillat oratio.

A expressão $a b$ ore pendere, usada por Inácio de Morais, é a mesma que Virgílio utiliza no verso 79 do livro IV da Eneida: Pendetque iterum narrantis ab ore. Refira-se, no entanto, que esta expressão se encontra também em Ovídio, Heroides 1.30: Narrantis coniunx pendet ab ore uiri, o que configura um exemplo revelador das muitas dificuldades que surgem no âmbito da determinação da intertextualidade.

Na segunda carta (fls. 53-54v $\mathrm{v}^{\circ}$, uma epístola que aborda essencialmente assuntos de ordem filológica, Inácio de Morais, recorrendo à adaptação de parte do verso 267 do livro VI da Eneida com que se dá início às revelações sobre as coisas mergulhadas na escuridão e nas profundezas da terra: Pandere res alta terra et caligine mersas, procura caracterizar as trevas que, na sua opinião, envolviam os estudos da dialéctica em Portugal, comparando-os com as profundezas nevoentas dos Infernos: Adde quod et haec ipsa studia quibus implicor saepe cogunt in taetram labi barbariem dum res alta caligine mersae.

Na Oratio panegyrica ad inuictissimum Lusitaniae regem Diuum Ioannem tertium, uma oração proferida por Inácio de Morais, em nome da Universidade, no dia 8 de Novembro de 1550, como saudação a D. João III, aquando da sua visita a Coimbra, o humanista transcreve, com uma ligeira adaptação sintática (mudança de $3^{\mathrm{a}}$ para $2^{\mathrm{a}}$ pessoa da forma verbal), o segundo hemistíquio do verso 209 do livro I da Eneida, para ilustrar a coragem com que D. João III suporta os penosos golpes que o têm atingido, comparando-o, deste modo, a Eneias, que, depois da tempestade, apesar de atormentado por muitos cuidados, também simulava no rosto a esperança e escondia a dor no coração:

Sed memor humanae conditionis, omnia haec uulnera acerbissima pari constantia toleras et (ut ait poeta) premis altum corde dolorem.

A.1.208-209: Talia uoce refert curisque ingentibus aeger spem uultu simulat, premit altum corde dolorem. 
$\mathrm{Na}$ Oratio funebris in interitum serenissimi regis Ioannis, que constitui uma das várias manifestações de luto da Academia Conimbricense pela morte de D. João III em 1557, Inácio de Morais cita o verso 95 do livro VI da Eneida para dizer que D. João III, apesar das muitas provações que teve de suportar ${ }^{15}$, cumpria alegre e espontaneamente aquilo que, em Virgílio, a Sibila de Cumas aconselhou a Eneias: não ceder à desgraça e, pelo contrário, ser cada vez mais ousado:

Sponte et alacriter illud praestabat quod apud Virgilium Sibylla Aeneam hortatur: "tu ne cede malis, sed contra audentior ito».

A. 6.95: Tu ne cede malis, sed contra audentior ito.

Como pudemos verificar, são várias as reminiscências virgilianas e os seus ecos ao longo da obra de Inácio de Morais. As marcas da leitura de obras de Virgílio -a Eneida mais do que as Bucólicas e estas mais do que as Geórgicas - são visíveis, em alguns casos reconhecidamente, noutros apenas no campo da suposição, na transcrição ou adaptação de versos inteiros, hemistíquios, ou simples expressões, ou através de oportunos paralelismos ou comparações entre figuras ou factos, para ilustrar acontecimentos.

Em suma, Inácio de Morais soube, com notável mestria e sensibilidade, fazer uso da obra virgiliana para, seguindo um dos preceitos da criação poética no Renascimento, dar ainda maior brilho e majestade às suas inspiradas obras.

\section{BIBLIOGRAFIA CITADA}

Bigalli, D. (1985): Immagini del Principe. Ricerche su politica e umanesimo nel Portogallo e nella Spagna del Cinquecento. Milano, Franco Angeli.

BucK, A. (1980): L'eredità clássica nelle letterature neolatine del Rinascimento. Brescia, Paideia.

CASTRO, A.P. (2008): Retórica e Teorização Literária em Portugal. Do Humanismo ao Neoclassicismo. Lisboa, INCM.

${ }^{15}$ Assistiu à morte de todos os seus filhos e de quase todos os seus irmãos. Sobre as virtudes régias e os modelos de comportamento a serem seguidos e imitados, Bigalli (1985: 91-115). 
Couto, A.P. (2002): "André de Resende e Inácio de Morais na questão dos causíficos». Em: Cataldo \& André de Resende. Actas do Congresso Internacional do Humanismo Português. Lisboa, Centro de Estudos Clássicos, págs. 79-91.

- (2003): «O drama da morte do príncipe D. João na poesia de Inácio de Morais». Em: Damião de Góis na Europa do Renascimento. Braga, UCP, págs. 681-701.

- (2004): Inácio de Morais. Percurso biográfico e literário de um Humanista de Quinhentos. Lisboa, Fundação Calouste Gulbenkian-Fundação para a Ciência e Tecnologia.

FerreIrA, A. (2000): Poemas Lusitanos. T.F. Earle (ed.). Lisboa, Fundação Calouste Gulbenkian.

GALÁN SÁNCHEZ, P.J. (2007): «La poética de la imitación en la poesia neolatina del Renacimiento: distinción entre fuentes, clichés y paralelos». Minerva, 20, págs. 139-161.

García Galiano, A. (1992): La imitación poética en el Renacimiento, Kassel, Reichenberg.

Machado, B. (1965-1967): Bibliotheca Lusitana, Coimbra, Atlântida Editora, vol. II, págs. 544-545.

MARTíN ACERA, F. (1987): «La imitatio como principio essencial en la creación poética del Renacimiento». Em Morocho Gayo, G. (coord.): Estudios de drama y retórica en Grecia y Roma. Léon, Universidade de Léon, págs. 323-338.

MARTín JiménEZ, A. (2015): «La imitación y el plagio en el Clasicismo y los conceptos contemporáneos de intertextualidad e hipertextualidad». Dialogía, 9, págs. 58-100.

Mclaughlin, M.L. (2001): Literary imitation in the Italian Renaissance. The theory and practice of literary imitation in Italy from Dante to Bembo. Oxford, Clarendon Press.

Melo, A.M.M. (2011): "Da Antiguidade ao Renascimento: os exempla e a promoção de um ideal de perfeição humana». Anuario de Estudios Filológicos, 34, págs. 125-137.

Miró Martí, O. (2017): «Introducción». Em Bembo, P. e Il Pico della Mirandola, G.F.: De imitatione. Sobre la imitación. New York, IDEA.

PEREIRA, V.S. (2000a): Aegidius Scallabitanus. Um diálogo sobre Fr. Gil de Santarém. Lisboa, Fundação Calouste Gulbenkian-Fundação para a Ciência e Tecnologia. 
- (2000b): «A veia retórica de Inácio de Morais ou os tons ovidianos de um infelix uates». Em: A retórica greco-latina e a sua perenidade. Coimbra, Fundação Eng. António de Almeida, vol. II, págs. 753-769.

PINHO, S.T. (1987): Lopo Serrão e o seu Poema da Velhice. Coimbra, INIC.

RAMAlHO, A.C. (1985): Latim Renascentista em Portugal (antologia). Coimbra, INIC.

RUIZ PÉREZ, P. (2015): «Prácticas y ofícios de narrar en el siglo XVI: historia y teoria». Studia aurea, 9, págs. 9-48.

SALTARELLI, T. (2009): «Imitação, emulação, modelos e glosas: o paradigma da mímesis na literatura dos séculos XVI, XVII e XVIII». Revista Aletria, 19, págs. 251-264.

SANTOS, R.M.F.N. (2016): «Nada se perde, tudo se transforma: a imitação dos modelos como princípio de criação artístico-literária. 2. A imitação no Renascimento italiano». Revista Investigações, 29.1, págs. 1-38.

SOARES, N.N.C. (1993): «A literatura de sentenças no humanismo português: res et uerba». Em: Humanismo Português na época dos descobrimentos. Coimbra, IEC-CECH, págs. 377-410.

- (2018): «Mitos, imagens e motivos clássicos na poesia trágica renascentista em Portugal». Em Soares, N.N.C.: Mostras de sentido no fluir do tempo. Estudos de Humanismo e Renascimento. Coimbra, Universidade de Coimbra, págs. 141-159.

SoARes, N.N.C. e TeIXeIRA, C. (coords.) (2017): Legado Clássico no Renascimento e sua receção: contributos para a renovação do espaço cultural europeu. Coimbra-São Paulo, Imprensa da Universidade de CoimbraAnnablume.

TeIve, D. (1999): Tragédia do Príncipe João. N.N.C. Soares (ed.). Coimbra, FCGFCT.

VIRGílio (1977-1980): Énéide (3 vols.). J. Perret (ed). Paris, Les Belles Lettres.

- (1982): Géorgiques. E. de Saint-Denis (ed.). Paris, Les Belles Lettres.

- (1983): Bucoliques. E. de Saint-Denis (ed.). Paris, Les Belles Lettres.

Aires Pereira Do Couto Universidade Católica Portuguesa aires.couto@ucp.pt 0000-0002-5930-7571 